\title{
Instructional Strategies to Support Creativity and Innovation in Education
}

\author{
Thapanee Seechaliao ${ }^{1}$ \\ ${ }^{1}$ Department of Educational Technology and Communications, Faculty of Education, Mahasarakham University, \\ Thailand \\ Correspondence: Thapanee Seechaliao, Department of Educational Technology and Communications, Faculty of \\ Education, Mahasarakham University, Thailand. E-mail: thapanee.see@msu.ac.th
}

Received: April 14, 2017

Accepted: May 16, 2017

Online Published: July 9, 2017

doi:10.5539/jel.v6n4p201

URL: http://doi.org/10.5539/jel.v6n4p201

\begin{abstract}
The purpose of the study focused on the instructional strategies that support creation of creative and innovative education. The sample for this study consisted of 11 experts in the field of instructional strategies that support innovation of education. Among them, five were specialists in design and development of teaching and learning, three were in technology and innovational education, and the other three were in the design and development of innovative teaching. Research instruments used in this study were three sets of interview questions designed for those specialists in their own expertise. Collected data was analyzed and categorized into key issues and themes based on literature. The results were presented through the form of descriptive analysis. The findings revealed that instructional strategies which support the creation of creative and innovative education should focus on system approach. The instructional strategies usually based on design based learning, problem solving, creative problem solving, creative thinking, research based learning, problem based learning, project based learning, science, or innovative teaching process could lead to innovative education creatively. Teaching that involves practicalities should also be focused. These instructional strategies have common elements and processes: problems in the beginning, solutions findings, testing, and evaluation. Also, using a variety of stimulating ideas to find possible solutions to the problems facilitates brainstorming and helps learners think about new ideas. Results also showed that instructional strategies using questions, classroom discussion, self-directed study, inductive and deductive thinking, media or social media make students engage students in learning activities and create innovation in learning.
\end{abstract}

Keywords: instructional strategies, creating innovative education, innovative learning, creativity, innovation

\section{Introduction}

Information and communication technology have evolved and changed rapidly in the last few decades. Education needs to catch up with the new technology and integrate it into courses. Also, innovation in education needs to follow the changing world and solve educational problems effectively (Whattananarong, 2011). Good quality innovation in education could make learners learn more in a shorter time and could promote learning competence. Therefore, it is crucial and indispensable to create good quality innovation in education. Sintapanon (2009) mentioned that creating innovation in education is vital for learning because it helps learners understand content and lesson clearly. Learners develop their learning processes which affect their desirable characteristics. Hence, creating educational innovation needs to be studied in each type of innovation.

In Education Program in Mahasarakham University, Thailand, most students are required to take a course that emphasizes the abilities to design, develop, implement, and evaluate educational innovations. This course is not only to develop students' abilities to design and create innovations in education, but it also helps enhance their $21^{\text {st }}$ Century learning skills in creativity and innovation. Additionally, it supports Thailand 4.0 educational policy, which aims to prepare Thai digital learners to learn by themselves and work with others via the internet and smart devices, as well as to ensure they could create new things from new knowledge around the world to serve the social needed. In response to Thailand 4.0 policy and the needs for $21^{\text {st }}$ Century learning skills, pre-service teachers need to be prepared for teaching in the near future (Faculty of Education, Mahasarakham University, 2016). However, there is room for improvement in pre-service curricula (Kanchanachaya, 2012). Kanchanachaya (2012) studied current preservice teacher preparation courses, especially the courses concerning 
creation of instructional media for practical teaching, and he suggested that many key components should be taken into account when designing courses, including analytical thinking, critical thinking, opinions sharing, expressing rational ideas, and open mindedness development. Although varieties of interesting media were used to support instruction and provide opportunities for learners to acquire knowledge and to search information from new resources anytime anyway, learners lacked in thinking diversity, versatility of instruction in group procedures was inadequate, and the course assignments in both quantity and quality were improper (Kanchanachaya, 2012). Khammani (2010) emphasized that if lecturers do not understand the topics they would be teaching, it is almost impossible to make others understand those topics. Therefore, lecturers need to know the notion of the content they will be teaching, instructional strategies, as well as pedagogical content knowledge, in order to conduct their instruction effectively and efficiently. With good quality instruction, it could facilitate students' learning abilities, enrich students' experiences, develop critical thinking processes, and endeavor to create innovations in education to achieve their goals.

Instructional strategy is a concept, guideline, approach, or main line to conduct, measure and evaluate instruction. Therefore, an instructional strategy needs to take into account many instructional components before it is implemented, such as learners, learning objectives, contents, learning context, overall context, conditions and lecturers' skills in selecting learning principles, techniques to accomplish the learning objectives they specified. The principles of designing instructional strategies are aligned with both lecturers' teaching skills and learners' learning styles (The royal institute, 2012). In previous studies, Songkhram (2013) stated that instructional strategies of creating innovation could change learners to innovators. In order to better develop students' characteristics, Padkasem, Niyomsrisomsak, and Rodjarkpai (2013) recommended the use of case study, problem-based learning, project-based learning, as well as role model and service learning in classroom teaching to engage students in active learning.

Creativity affects how to deliver instruction, which is essential in design courses and innovation creation courses in pre-service preparation. Creativity is a crucial thinking skill to create educational innovation, which is novel, valuable, and useful in education. Past research showed that developing a systematic instructional model focusing on enhancing creative thinking could effectively improve students' ability to creativity (Prompan, 2007) and creative problem solving (Kanchanachaya, 2012). However, the previous research did not focus on integrating creativity in creating innovation in education. This research aimed to study the instructional strategies that support creation of creative and innovative education. The results would find the appropriate ways for teaching and be the guideline to support and develop learners' competence to design and create innovation with more creativity and higher quality.

\section{Literature Review}

\subsection{Innovation in Education}

Innovation should be a new thing or partial new one that is created by a systematic approach and then improved by doing research, and it is not appeared in a daily working system (Songkhram, 2013). The common procedures in creating educational innovation are as follows: 1) study problems or need, 2) specify the problem, 3) specify the goals, 4) study the limitation, 5) create the educational innovation, 6) develop the educational innovation, 7) diffuse the educational innovation, and 8) study the effects of diffusion's educational innovation (Kaewpradit, 2002; Khammani, 2013; Phumipak, 2006).

In a world of rapid change in information and communication technology, innovation in education needs to keep updated and get prepared for this changing world in order to solve educational problems effectively (Whattananarong, 2011). Generally, educational innovation is divided to six types: 1) media and educational technology, 2) instructional technique/pedagogy, 3) curriculum, 4) educational system, 5) measure and evaluation, and 6) administration and management (Academic Department, Ministry of Education, 1993; Chaikitpinyo, 2006; Sintapanon, 2009; Sittisomboon, 2014; Sutthirat, 2016). First two of six types are most frequently introduced in Media and Educational Technology or related courses in Thailand.

Songkhram (2013) said that innovation is products, techniques, new procedures, new knowledge that have been never happened or, existed products, techniques, procedures but revised or developed and good results. Therefore, creating an innovative product need to be followed the learning activities that help students create innovation by themselves. These activities are the important procedures including diverse procedures and technique. These activities were explained very detail. Teachers can apply these activities in their classroom efficiency, and proposed that a tool to evaluate innovation should include three parts: 1) standarded procedures of innovation development, 2) degree of valuable innovation, and 3) innovative characteristics. A composite 
score from these three types of rubrics indicates an innovation level. If the score of innovation is at a low level, it should be revised to make more innovative.

\subsection{Creativity in Education}

Creativity is a crucial thinking skill to create educational innovation that is novel, valuable, and useful in education. Many creative instructional models have been used in higher education to promote creative thinking. For example, Prompan (2007) developed a WEB-based instructional model based on Brain-Based learning process in a design course to enhance creative thinking of undergraduate students. This model consisted of principles, objective, instructional process, and evaluation. The principles emphasized the importance of supporting environments that can motivate learners to maximize their readiness in order to generate optimal learning processes. The principles also emphasized the importance of design of problem solving activities and of challenging tasks for learners. The instructional process was composed of seven stages: 1) preparation, 2) setting the learning goals, 3) learning and transformation, 4) defining the concept and application, 5) development, 6) presentation, and 7) evaluation and celebration of the learning. The implementation of this model could increase students' creativity (Prompan, 2007). Chuathong (2010) used collaborative learning and synectics instruction to foster pre-service teachers' creative thinking. Chuathong (2010) model consisted of six components: 1) Learning Management System (LMS) on virtual classroom, 2) collaboration and communication tools, 3) learning contents, media and resources, 4) roles of learners and instructors, 5) learning activities, and 6) assessment. There were three steps of collaboration learning in this model: 1) pre-learning operation, 2) learning operation, and assessment. Aulpaijidkul (2011) applied a six-thinking-hats technique in a fundamental arts subject for five weeks, and his study showed that undergraduate students' creative thinking was improved after the completion of this learning. Even students who originally had different levels of creative thinking could get benefits and increased. Kanchanachaya (2012) developed a blended learning model which used lateral thinking to enhance creative problem solving abilities in instructional media production courses for pre-service teachers. Kanchanachaya (2012) identified five input factors: 1) content, 2) learners, 3) instructors/assistant instructors, 4) technologies used in teaching and learning, and 5) assessment and evaluation. Four steps in this learning process of the model included: 1) preparation, 2) study content based on course objectives, 3) blended learning approach following the creative problem solving principles using lateral thinking, and 4) evaluation. The findings of the study showed that this learning model could enhance creative problem solving abilities. Chitcharoen (2014) proposed a teacher training approach to enhance teacher competency in educational innovation and information technology course for pre-service teacher education. The teacher training process composed of 4 components: 1) people in a teacher network, 2) a teacher competency in educational innovation and information technology, 3) technology tools, and 4) evaluation. The development phase composed of 4 steps: 1) increases knowledge, 2) design stage to actual implementation, 3) join the network, and 4) to share the experience.

Creativity of new products always use standard's tools of evaluation. These evaluation tools are composed of three dimensions and 11 concepts. The first dimension is novelty, which includes three concepts: originality, surprising, and germinality. The second dimesion is resolution, which involves three concepts: valuable, logical, and useful. The third dimension is elaboration and synthesis, which comprises five concepts: elegant and well-crafted, complex, understandable, efficiency, and useful (Cropley, 2000).

\subsection{Instructional Strategies}

Instructional strategy is a concept, guideline, approach, or main line to conduct instruction, measure and evaluation. Instructional strategy is one of crucial components to conduct instruction for accomplishing the instructional goals. To develop a better instructional strategy, the following instructional components need to be analyzed: learners, learning objectives, contents, learning context, overall context, condition and lecturers' skills in selecting the learning principles, technique to accomplish the learning objectives they needed. Designing instructional strategies focuses on both lecturers' teaching skills and learners' learning styles (The royal institute, 2012).

There were previous researches concerning instructional strategies in higher education. For example, Padkasem et al. (2013) studied the strategies in developing students' characteristics according to learning outcomes of general education at Burapha University. The results showed that mostly concern student centered learning using active learning. The active learning strategies were: case study, problem-based learning, and project-based learning. Two teaching strategies mostly used were role model and service learning. These strategies were highly recommended to be used in classroom teaching. Songkhram (2013) said creating innovation could change learners to innovators and descripted the instructional strategy for developing an educational innovation. This instructional strategy were followed: 1) prepare for creating innovation, 2) specify the interested topic, 3) share 
knowledge, experience, and opinion, 4) plan for creating an innovation, 5) create an innovation, 6) implement an innovation, 7) present an innovation, and 8) evaluation. Kanchanachaya (2012) studied the development of a blended learning model based on creative problem solving principles using lateral thinking to enhance creative problem solving abilities for instructional media production of pre-service teachers. This model had five input factors: 1) content, 2) learners, 3) instructors/assistant instructors, 4) technologies used in teaching and learning, and 5) assessment and evaluation. This learning process of the model included four steps: 1) preparation, 2) study content based on course objectives, 3) blended learning approach following the creative problem solving principles using lateral thinking, and 4) evaluation. The output of this model was creative problem solving abilities.

\section{Research Methodology}

\subsection{Objective}

The objective was to investigate the guides on how to design the instructional strategies that support creation of creative and innovative education.

\subsection{Sample}

The sample for this study consisted of eleven experts in the field of instructional strategies that support innovation of education. Among them, five were specialists in design and development of teaching and learning, three were in technology and innovational education, and the other three were in the design and development of innovative teaching. All experts were selected by snowball sampling technique. They all have experiences in the field of instructional strategies supporting innovation of education for least five years, and/or have experiences in writing a handbook or conducting research in these related fields. All experts were well-known in education fields in Thailand.

\subsection{Research Instrument}

The research instrument used a semi-structured interview with open questions related creative and innovative education. It contained three sets of interview questions designed for those specialists in their individual expertise. The common sample questions are as follows:

1) What are the most related types of innovation to the course description of Media and Educational Technology course that is addressed in Bachelor of Education Program in your university?

2) What kind of instructional strategies do you use to support learners to enhance creativity and create educational innovations?

3) What is the most helpful activity to motivate learners to enhance creativity and create educational innovations?

The instrument was validated by five experts in the related fields: one expert in educational technology and innovations, one in designing and developing an educational innovation, one in instructional design and development, and two in educational research and measurement, using the index of Item-Objective Congruence (IOC) measure (Rovinelli \& Hambleton, 1977). The IOC values ranged from 0.60 to 1.00, and it indicated that was suitable for conducting the study. The instruments were pilot tested with three lecturers from Mahasarakham University and Khonkhean University in Thailand.

\subsection{Data Collection}

The data was collected through these three sets of interview questions. Eleven experts participated in the study. The interviews were conducted between May 30, 2016 and June 29, 2016. After the completion of all interviews, collected data was analysed and categorized into key issues and themes based on literature. The results were presented through the form of descriptive analysis.

\section{Results}

Eleven experts whom participated in the study gave the interviews. They explained their experiences and gave the examples how to design the instructional strategies supporting creation of creative and innovative education as following thees themes.

\subsection{The Instructional Strategies Which Support the Creation of Creative and Innovative Education}

The findings revealed that instructional strategies which support the creation of creative and innovative education should focus on systematical development. The instructional strategies that usually develop based on design-based learning, problem solving, creative problem solving, creative thinking, research-based learning, 
problem-based learning, project-based learning, science, or innovative teaching process could lead to innovative education creatively. Teaching that involves practicalities should also take these instructional strategies into consideration.

\subsection{The Common Elements and Processes of These Instructional Strategies}

The findings indicated these instructional strategies have common elements and processes, including problems in the beginning, solutions findings, testing, and evaluation. Also, using a variety of stimulating ideas to find possible solutions to the problems could facilitate brainstorming and help learners think about new ideas. Results also showed that instructional strategies using questions, classroom discussion, self-directed study, inductive and deductive thinking, or media could engage students in learning activities and help them create innovation in learning.

Moreover, collaborative learning and place-based learning should be emphasized by intervening techniques that should be implemented to promote creative and innovative learning.

\subsection{The Techniques Which Used for Instructional Strategies}

The findings showed techniques that were used for instructional strategies are as follows:

1) Brainstorming, collaboration, discussion, team-base/group work, project-based learning, or anything could stimulate critical ideas, such as using questions technique and six thinking hats of Edward de Bono technique, etc. Lecturers should provide feedback for learners regularly.

2) Thinking outside the box technique. Questions inspire learners to think of new ideas. For example, learners could think of the alternatives, think of new things, think outside the box, think like six thinking hats, and think of techniques to brainstorm. Techniques of using questions and media to create originality are also mentioned.

3) Technique of providing challenging questions to think creatively.

4) Providing feedback or reinforcement technique. There should be positive reinforcement by giving prizes rather than things. It should be gamification, or games that have prizes which are challenging, fun, and modern. It should add levels of challenge and difficulty, and the rewards are given away regularly. In addition, the activities must be learners centered.

5) Technique that is applied to a game show or competition activities.

6) Instructional techniques that use the following methods, 6.1) Teaching by lecturing. It should not be used too often. 6.2) Teaching by demonstrating. 6.3) Teaching by using small group discussion. 6.4) Teaching by using simulations. 6.5) Using field trip as a teaching technique. 6.6) Teaching by using induction. 6.7) Teaching by using deduction.

7) Teaching that creates motivation for learners, according to ARCS Model theory, such as 7.1) attention, 7.2) relevance, 7.3) confidence, and 7.4) satisfaction of learners.

8) Using up-to-date technology to design instructional activities. In order to make learners innovate creatively, instructional strategies and elements of instructions should serve as a guideline to contribute to an instructional process for achieving learning objectives as planned. With regard to instructional measurement and evaluation, teachers must design instructional strategies that are suitable for 1) characteristics and potential of learners, 2) learners' learning styles, 3) subject matters, 4) learning activities, 5) contexts of each university, 6) environments, and 7) the availability of technology.

\subsection{The Recommendation Which Should Design These Instructional Strategies}

Nowadays, learning behaviors have changed. Learners like to learn with social media and mobile devices. They can learn anytime everywhere they want and enjoy learning with peers. Therefore, Lecturers need to apply social media and mobile devices to their courses and need to make their courses more interesting. For example, a new instructional strategy called flipped classroom has been implementing in both classroom and online learning environments. Lecturers assign learning materials for leaners to read and required them to participate in learning activities on social media before the class has started in a classroom. During the class session, learners are engaged in learning activities, discuss, problem solving, brainstorming with peers and working projects collaboratively.

Therefore, creating innovation in education creatively is diversified in different context, so does the creativity. 


\section{Discussion}

The instructional strategies usually based on design-based learning, problem solving, creative problem solving, creative thinking, research-based learning, problem-based learning, project-based learning, science, or innovative teaching process could lead to learning outcomes that support creation of creative and innovative education in these courses. These results are similar to the strategies to develop students' characteristics according to learning outcomes which were mostly concern student-centered learning using active learning. The active learning strategies were: case study, problem-based learning, and project-based learning. Two teaching strategies mostly used were role model and service learning. These strategies were highly recommended for classroom teaching (Padkasem et al., 2013).

Learners can create innovation creatively as long as they follow the proper instructional strategies. The instructional strategies include three crucial instructional components: planning a guideline to conduct instruction, evaluation, and achieving learning objectives. Specifically, developing instructional strategies needs to analyze many common instructional components, such as learners, learning objectives, contents, learning context, overall context, conditions, lecturers' skills in selecting learning principles, and techniques to accomplish learning objectives. Designing instructional strategies focuses on lecturers' teaching skills and learners' learning styles. These results are similar to Songkhram's (2014) study. In her study, Songkhram (2014) identified four crucial components for creating innovation: lecturers, learners, environments, and technology. The model used to develop creativity of undergraduate students in a design course was consisted of principles, objective, instructional process, and evaluation. The principles emphasized the design problem solving activities and challenging tasks for learners (Prompan, 2007). The model was to develop pre-service teachers' creative thinking that consisted of 6 components: 1) Learning Management System (LMS) on virtual classroom, 2) collaboration and communication tools, 3) learning contents, media and resources, 4) roles of learners and instructors, 5) learning activities (for small group and large group), and 6) assessment (Chuathong, 2010). The model was to enhance creative problem solving abilities for instructional media production of pre-service teachers had five input factors: 1) content, 2) learners, 3) instructors/assistant instructors, 4) technologies used in teaching and learning, and 5) assessment and evaluation (Kanchanachaya, 2012). The teacher training process was to enhance teacher competency in educational innovation and information technology that composed of four components: 1) people in a teacher network, 2) a teacher competency in educational innovation and information technology, 3) technology tools, and 4) evaluation (Chitcharoen, 2014). A digital storytelling design model using concept map on blog to enhance creative thinking of undergraduate students that consisted of six elements: 1) motivation, 2) objectives, 3) contents, 4) experience, 5) activities, and 6) evaluations (Thanajun, 2012).

The findings revealed that instructional strategies which support the creation of creative and innovative education should focus on systematical development. These instructional strategies have common elements and processes: problems in the beginning, solutions findings, testing, and evaluation. Also, using a variety of stimulating ideas to find possible solutions to the problems can facilitate brainstorming and help learners think about new ideas. These results are similar to some studies which indicated common process of creating educational innovation (Kaewpradit, 2002; Khammani, 2013; Phumipak, 2006; Songkhram, 2014). For example, in the process of creating innovation, Songkhram (2014) pointed out that the output is innovation, and the feedback is the results of the followed steps of creating innovation and learners' evaluations (Songkhram, 2014). Other previous studies also indicated common processes in creating educational innovation: 1) study problems or needs, 2) specify problems, 3) specify goals, 4) study limitation, 5) create educational innovations, 6) develop educational innovations, 7) diffuse the educational innovation, and 8) study the effects of diffusion's educational innovation (Kaewpradit, 2002; Khammani, 2013; Phumipak, 2006). These results are similar to some researches indicated that the model was to enhance creative thinking of undergraduate students were seven stages: 1) preparation; 2) setting the learning goals; 3) learning and transformation; 4) defining the concept and application; 5) development; 6) presentation; and 7) evaluation and celebration of the learning (Prompan, 2007). The model was to develop pre-service teachers' creative thinking that were 3 steps of collaboration learning: 1) pre-learning operation, 2) learning operation, 3) assessment (Chuathong, 2010). The undergraduate students with different creative thinking levels studying the web-based collaborative learning with a discussion board using six thinking hats technique in fundamental arts subject learning had enhanced creative thinking (Aulpaijidkul, 2011). The learning process of the model included four steps which were: 1) preparation, 2) study content based on course objectives, 3) blended learning approach following the creative problem solving principles using lateral thinking, and 4) evaluation. The output was creative problem solving abilities (Kanchanachaya, 2012). The development phase composed of four steps: 1) increases knowledge, 2) design stage to actual implementation, 3) join the network, and 4) to share the experience (Chitcharoen, 2014). A digital storytelling design model using concept 
map on blog to enhance creative thinking of undergraduate students that consisted of seven steps: 1) preparing students, 2) analyze, 3) brainstorm, 4) creation and improvement, 5) presentation, 6) evaluation, and 7) publicity (Thanajun, 2012).

Today, learners like to learn with social media and mobile devices. They enjoy learning together all the time they needed. Therefore, Lecturers need to design their class to be more interested and challenged both in classroom and online that was called flipped classroom. They assigned the learning activities for learners to read and learn on social media before starting the class in classroom. In the classroom, they assigned the learning activities to discuss, brain storm with peers and do a project together. These results are similar to some studies indicated that learning styles of digital person who were in Generation Z (Nahipon, 2015). In Thailand, most students like to learn in collaborative styles. They like to learn, work and share their opinions with friends, teachers and others. They deemed that classroom was a place for interaction with each other (Nahipon, 2016). These results show the satisfaction on learning with social media. Thanajun (2012) developed a digital storytelling design model using concept map on blog to enhance creative thinking of undergraduate students. The result showed that students could effectively improve their creative abilities and showed how to use social media. Moreover, the lecturers' behaviors and beliefs regarding social media in higher education showed the most frequently used social media that were YouTube, Facebook, and Slideshare. The believed that social media were easy to use and could save time and money for online courses; furthermore, they reported that social media could be a tool for teaching, enhancing collaborative learning, and improving project abilities (Seechaliao, 2014). Therefore, designing instruction strategy would use social media and mobile devices as learning tools. It could support learning styles of digital learners and motivate their learning that is more suitable for $21^{\text {st }}$ Century Learning.

\section{Conclusion}

Instructional strategies that support learners to create innovation in learning creatively aim to create a thinking process, especially the creativity in thinking something new and different. Instructional strategies for learners to have innovative education should come from groups or teams, shared knowledge, team solutions, and consensus ideas. In addition, there are two parts of teaching. First is theories, and second is practices that are assigned for students to conduct projects. Instructional strategies should focus on student learning and should be implemented in lessons gradually particularly when discussing with the experts. Lastly, instructing students to be able to create innovation in learning creatively can be taught at every level. The difficulties of the ideas could be varied, depending on the contexts and the instructional designs by instructors. Although developing creativity and innovation in education is challenging, it is important and necessary to facilitate learners to obtain these abilities which also prepare them to success in their future complex work environments.

\section{Acknowledgments}

This work has been supported by the Mahasarakham University Development Fund, Mahasarakham University, Thailand under the international conference grant.

\section{References}

Academic Department, Ministry of Education. (1993). Development of efficiency instructional innovation to enhance learners' learning. Bangkok, Thailand: Kurusapa Printing.

Aulpaijidkul, N. (2011). Effects of web-based collaborative learning with a discussion board using six thinking hats technique in fundamental arts subject on creative thinking of undergraduate students with different creative thinking levels. Bangkok, Thailand: Chulalongkorn University.

Chaikitpinyo, S. (2006). Learning and teaching innovation. Journal of Learning and Teaching Innovation, 3(3), 13-15.

Chitcharoen, P. (2014). Development of teacher training process with a teacher network and Design-based approach to enhance teacher competency in educational innovation and information technology. Bangkok, Thailand: Chulalongkorn University.

Chuathong, S. (2010). Development of a virtual classroom model using collaborative learning and synectics instruction to develop pre-service teachers' creative thinking. Bangkok, Thailand: Chulalongkorn University.

Cropley, A. J. (2000). Defining and measuring creativity: Are creativity tests worth using? Roeper Review, 23(2), 72-79. https://doi.org/10.1080/02783190009554069

Faculty of Education, Mahasarakham University. (2016). Curriculum in education. Mahasarakham, Thailand: Mahasarakham University. 
Kaewpradit, A. (2002). Educational technology: Principles and concept to practices. Bangkok, Thailand: Thaksin University.

Kanchanachaya, N. (2012). Development of a blended learning model based on creative problem solving principles using lateral thinking to enhance creative problem solving abilities for instructional media production of pre-service teachers. Bangkok, Thailand: Chulalongkorn University.

Khammani, T. (2010). Qualifications framework for higher education: Teaching strategies. The Journal of the Royal Institute of Thailand, 35(2), 181-201.

Khammani, T. (2013). Teachers' pedagogy: Knowledge and the teaching profession. Bangkok, Thailand: Chulalongkorn University Press.

Nahipon, B. (2015, September). Learning styles of digital person. Paper presented at the 6th International Conference on Human Resource and Organization Management and Development (HROMD 2015), Bangkok, Thailand. Retrieved from http://www.hrd.nida.ac.th/hromd2015/UploadFile/datachange/datachange37_2015-09-10.pdf

Padkasem, N., Niyomsrisomsak, S., \& Rodjarkpai, Y. (2013). The strategies in developing students' characteristics according to learning outcomes of general education at Burapha University. Journal of Education and Social Development, 9(1), 44-54.

Phumipak, C. (2006). Diffusion of innovation. Communication Technology, 13(1), 109-128.

Prompan, I. (2007). A development of a WEB-based instructional model based on Brain-based learning process in design course to enhance creative thinking of undergraduate students. Bangkok, Thailand: Chulalongkorn University.

Rovinelli, R. J., \& Hambleton, R. K. (1977). On the use of content specialists in the assessment of criterion-referenced test item validity. Dutch Journal of Educational Research, 2, 49-60.

Seechaliao, T. (2014). Lecturers' behaviors and beliefs regarding social media in higher education at the Faculty of Education, Mahasarakham University. Journal of International Education Research, 10(2), 155-160.

Sintapanon, S. (2009). Educational Innovation to develop youth's quality (3rd ed.). Bangkok, Thailand: 9119 Technic Printing.

Sittisomboon, M. (2014). Development of educational innovation. Phitsanulok, Thailand: Naresuan University.

Songkhram, N. (2013). Creating innovation: Changed learners to innovators. Bangkok, Thailand: Chulalongkorn University Press.

Songkhram, N. (2014). Innovation-based learning, new concept: Changed learners to innovators. In P. Koraneekij, N. Songkhram, \& J. Khlaisang (Eds.), Articles of educational technology and communications: Blended learning innovation (pp. 79-98). Bangkok, Thailand: Chulalongkorn University Press.

Sutthirat, C. (2016). 80 Innovations with learner-centered approach (7th ed.). Nonthaburi, Thailand: P Balance Design and Printing.

Thanajun, P. (2012). The development of a digital storytelling design model using concept map on blog to enhance creative thinking of undergraduate students. Bangkok, Thailand: Chulalongkorn University.

The Royal Institute. (2012). Dictionary of Education. Bangkok, Thailand: The royal institute.

Whattananarong, K. (2011). Innovation and technical education technology. Bangkok, Thailand: King Mongkut's University of Technology North Bangkok.

\section{Copyrights}

Copyright for this article is retained by the author(s), with first publication rights granted to the journal.

This is an open-access article distributed under the terms and conditions of the Creative Commons Attribution license (http://creativecommons.org/licenses/by/4.0/). 